\title{
THERMO-MECHANICAL PROPERTIES OF NITI CLOSED COIL SPRINGS - FORCE DEGRADATION AND FORCE REGENERATION OVER TIME, VISCOUS PROPERTIES
}

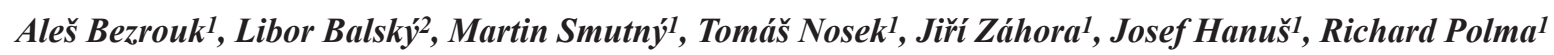

Charles University in Prague, Faculty of Medicine and University Hospital in Hradec Králové, Czech Republic: Department of Medical Biophysics ${ }^{1}$; Private orthodontist, Hradec Králové, Czech Republic ${ }^{2}$

\begin{abstract}
Summary: Introduction: The aim of this study was to find out the impact of degradation and regeneration of force over time at NiTi springs on the value and course of the final acting force and to verify the possibility of using these phenomena for a directed transition to the reverse plateau and its maintaining. Methods: Static and cyclic mechanical loadings were performed. At first unused springs were tested. Afterwards the springs were mechanically stabilized by stress cycling and finally tested again. The difference in shape of the working curves was assessed. For simulation and description of the force degradation the modified Voight model was used. Results: New springs, mainly those with large hysteresis, showed a significant stress-strain curve movement and shape changes during the cycling. The effect of the stress-strain curve course change disappeared fully in the stabilized springs. Multiple loading led to an overall decrease of force value during the measurement. The effect of force degradation and regeneration over time by simple static loading varies in the range of percentage of the nominal force in the plateau area. The transition between stress-strain curve phases caused by the degradation or regeneration of the force wasn't observed in case of mechanically stabilized springs. Conclusions: Springs should be mechanically stabilized before their application. The degree of force degradation over time is insignificant for mechanically stabilized springs. Degradation or regeneration of force over time, mechanical stabilization or micromovements in the mouth don't cause any transition between individual stress-strain curve phases.
\end{abstract}

Key words: Nitinol; Closed coil springs; Force degradation; Viscous properties

\section{Introduction and literature review}

Nickel-titanium (NiTi) SE closed-coil springs are nowadays frequently used in fixed orthodontic treatment. The advantage of NiTi super elastic (SE) springs - in comparison with steel springs, elastic chains or intraoral elastics - is the effect of nearly constant force in a wide deformation range. Using NiTi SE springs there should be almost no decrease in force during movement of teeth or closure of a gap. Significantly lower force degradation over time occurs for the constant extension than at conventional materials (4-8). The relevant constant NiTi springs force may be more biologically acceptable than the intermittent high force delivery of the elastic modules (8). The force of elastic chains decreases during 4 weeks by more than $50 \%$ (10). Use of excessive forces in space closure can cause besides damaging the periodontium, the alveolar bone and the roots - adverse effects such as loss of incisor torque control and loss of tip and rotational control of upper molars with relative extrusion of their palatal cusps, anchorage loss (9). The method we chose for tooth movement should be of the kind offering the maximum fast movement combined with minimal damage of the periodontium, alveolar bone or the root. The orthodontic tooth or teeth movements should be the result of influence of light and continually acting forces (1-3). The speed level of closing gaps is faster and more fluent at the NiTi springs than by the elastic modules (7-8, 11-12).

NiTi springs force properties are influenced by their geometric construction (length, diameter and pitch of the coil, wire diameter) and the material used (Young's module of elasticity, hysteresis, transition temperatures...) (13-15). This information is hardly available at most suppliers.

Having the knowledge of special works providing detail characteristics of the NiTi springs the orthodontist should not suppose that the spring properties remain unchanged within the whole time of usage.

A lot of questions occur. If admitting the force degradation over time at the NiTi spring, how significant will it be? And what about the mechanical stability? Will it influence the time force progress and is it able to eliminate or by contrast cause the transition to certain plateau phase even without preactivation $(1,4,12,16)$ ?

(Preactivation is recommended process of spring application. It means spring overextension then desired application length. It should be done before each application at the patient.) 


\section{The aims of our work}

- Testing mechanical stability of the spring

- Investigating the viscous properties and time force degradation of the spring

- Investigating the influence of spring time force degradation on possible transition between individual phases of close-coil springs chart (loss of plateau phase)

- Drawing possible consequences for common practice

\section{Material and Methods}

\section{Elastic properties of the material and geometric structure of the spring}

The elastic properties of a material define the wellknown Young's module of elasticity. They are given by material chemical composition of the spring and also by the crystalline structure (austenitic or martensitic phase depending on in which phase the material occurs). They influence the curve slope in its inconstant segment and also the size of nominal forces in constant segments of the stress-strain curve - the plateau.

Geometric spring structure - its working length, coil diameter, coil pitch, wire diameter, wire profile are key factors significantly influencing the load characteristics of the spring. They influence the curve slope in austenitic and martensitic segments, consequently the reverse plateau forces range, extension and slope. At simple spring shape the variation of forces can be easily solved analytically or by some numerical methods (14). Due to it the correct NiTi spring construction can be designed. The overall behavior of the spring and hence the reproducibility of measurements is related to the whole set of design-mechanical properties and influences of external circumstances, such as formation of inclusions, structural failures and changes in general, but also mechanical tightness between the mounting eyelet and the spring - it is related to the construction of the eyelet and the spring, the mutual friction between materials and their compliance. The instability of the mechanical bond can cause mechanical slippage and changes in the individual measurements. Therefore mechanical stabilization of a new unused spring is suitable for some types of springs. It is achieved by several measuring cycles; see i.e. Wichelhaus et al. (16). Within "touching" the behavior of individual springs we always did "trial" measurements. For some new spring types significant decreases of forces, mechanical movements and shape changes of load characteristics between immediately following measurement cycles were noted. We performed a set of initial cycling. Further the springs were left for more than 1 day without load. Afterwards we cycled them repeatedly and investigated significant changes within cycling and radical changes of the working curves compared to the last previous measurement.

\section{Viscous properties of the material}

We expected the spring behavior according to the standard Maxwell-Wiechert (Voight) model (17). It means that NiTi springs will feature significant viscous properties described by viscous parameter besides elastic properties typical for any spring. The initial cycling showed highly individual behavior of different types of springs, and therefore each spring of a specific type requires specific testing approach. Actually the existence of viscous parameter led us to consider whether a time delay for complete spring regeneration between consecutive measuring cycles is necessary in terms of measurement reproducibility. Further an adjustment of movement speed during the measurement might be necessary in order not to disqualify the spring by improper testing. We carried out some consecutive cycles of spring extension and back under the same conditions as b) and progressively extended the time of regeneration (leaving the spring without load between consecutive cycles) and changed the extension speed. The impact of parameter changes on force dependence on extension with emphasis on reverse plateau changes within the stressstrain curve was analyzed.

Other calculated effect of the viscous parameter of spring is spontaneous and sufficiently fast (taking hours) transition to reverse plateau within the stress-strain curve. Due to it we designed and performed a set of measurements to know the time stability of spring force and discover their viscous properties. We extended the spring. Afterwards we measured the course of dependence of force on time at constant extension during certain time period. Later we tested the impact of force degradation on the course and shape of the spring load characteristic $(1,18)$.

The tests were realized at stable temperature of $37{ }^{\circ} \mathrm{C}$ $\left( \pm 0.1^{\circ} \mathrm{C}\right.$ ) by submersing the samples and fixtures in water bath. We measured dependence of force on extension. One measuring cycle means extension from the original length to the maximum possible extension in that cycle and back. Maximum extension in the first cycle was $1 \mathrm{~mm}$. We set the measurement method so that the maximum extension of each next cycle will always be $1 \mathrm{~mm}$ larger.

Tested spring types with certain measure parameters are shown in the table (Tab. 1).

For testing we used the equipment (Fig. 1) consisting of following parts:

Universal testing system Instron 3343 for measuring of force and lengthening. The load frame was equipped with $\mathrm{a} \pm 10 \mathrm{~N}$ static load cell.

Thermo-static water bath with an exchanger of own construction.

Measuring appliances of own construction are terminated with hooks with sharp arches in order not to allow the spring to move or rotate against the axis of measurement. The reason for that is to maintain the condition of measurement (length and diameter of the spring, formation of 
Tab. 1: Tested spring types with certain measure parameters

\begin{tabular}{|c|c|c|c|c|c|}
\hline \multicolumn{6}{|l|}{$9 \mathrm{~mm}$} \\
\hline \multirow[t]{2}{*}{ producer } & type & catalogue No. & $\begin{array}{l}\text { velocity } \\
{\left[\mathrm{mm} \mathrm{s}^{-1}\right]}\end{array}$ & $\begin{array}{l}\text { delay } \\
{[\mathrm{s}]}\end{array}$ & cycles \\
\hline & & & & & $\max$. ext. $[\mathrm{mm}]$ \\
\hline $3 \mathrm{M}$ & medium $200 \mathrm{~g}$ & $344-200$ & 2.0 & 10 & 12 \\
\hline $\begin{array}{l}\text { American } \\
\text { Orthodontics }\end{array}$ & $.030^{\prime \prime} / 0.76 \mathrm{~mm}$ & $855-180$ & 0.5 & 60 & 14 \\
\hline Dentaurum & tomas ${ }^{\circledR}$-coil spring light (blue) & $302-012-00$ & 1.0 & 20 & 12 \\
\hline Dentaurum & tomas ${ }^{\circledR}$-coil spring medium (yellow) & $302-012-10$ & 1.0 & 20 & 12 \\
\hline GAC & Light (100 grams) & $10-000-03$ & 2.0 & 30 & 12 \\
\hline GAC & Heavy (200 grams) & $10-000-01$ & 2.0 & 10 & 12 \\
\hline Ortho Organizers & $.010 \times .030(200$ grams $)$ & $100-622$ & 2.0 & 10 & 19 \\
\hline \multicolumn{6}{|l|}{$12 \mathrm{~mm}$} \\
\hline \multirow[t]{2}{*}{ producer } & type & catalogue No. & $\begin{array}{l}\text { velocity } \\
{\left[\mathrm{mm} \mathrm{s}^{-1}\right]}\end{array}$ & $\begin{array}{l}\text { delay } \\
{[\mathrm{s}]}\end{array}$ & cycles \\
\hline & & & & & $\max$. ext. [mm] \\
\hline $3 \mathrm{M}$ & medium $200 \mathrm{~g}$ & $346-200$ & 2.0 & 10 & 26 \\
\hline $\begin{array}{l}\text { American } \\
\text { Orthodontics }\end{array}$ & $.030^{\prime \prime} / 0.76 \mathrm{~mm}$ & $855-181$ & 2.0 & 10 & 26 \\
\hline Ortho Organizers & $.010 \times .030(200$ grams $)$ & $100-623$ & 2.0 & 10 & 29 \\
\hline
\end{tabular}

bending and torsion forces). Otherwise the negative factors (such as shift, torsion, rotation, bending, etc. of the spring) can considerably influence the results and give the impression of a "travelling force".

Thermostat Julabo F 25 for setting and keeping of chosen bath temperature. The accuracy of set temperature was $\left( \pm 0.1{ }^{\circ} \mathrm{C}\right)$.

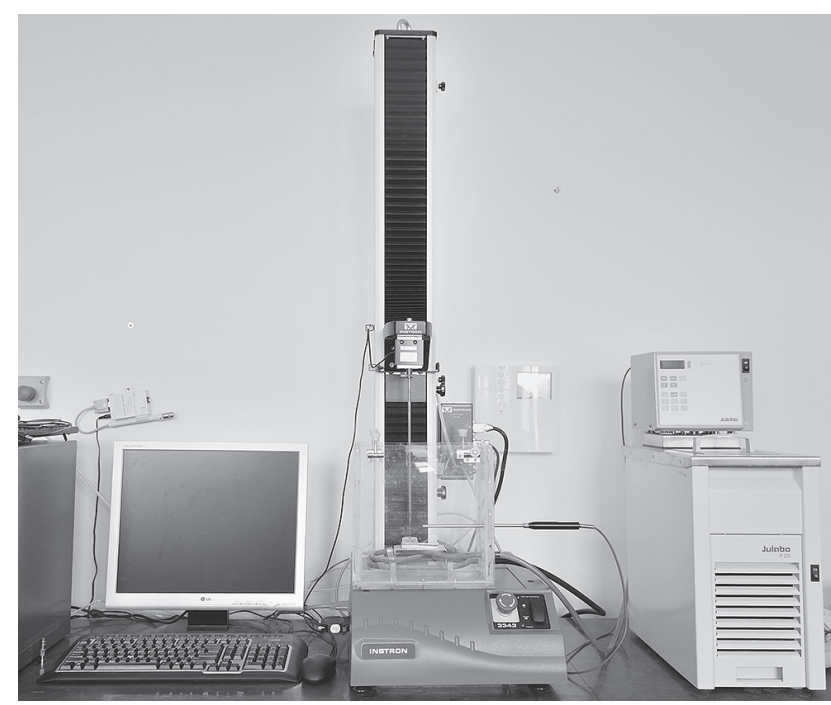

Fig. 1: Photo of testing equipment
Final data were processed with help of MS Excel 2007, NCSS 6.0.21 and CurveExpert version 1.40.

Based on the adapted Voight model we described the viscous properties by triple exponential function $F=A e^{-B t}+C e^{-D t}+E e^{-F t}+G$, applied on dependence of the force on time at constant temperature and extension, where: $F$ is force measured in newtons; $t$ is time measured in seconds; $A, C, E$ coefficients are measured in newtons and represent the contributions of three different types of viscous exponential force decreases to the overall force degradation over time; $B, D, F$ are measured in reciprocal seconds and represent the rates of viscous exponential force decreases. The resulting force after the force degradation process (limit for time $\rightarrow \infty$ ) is represented by the element $G$-measured in newtons (17). This function enables prediction of spring behavior with reasonable accuracy in longer time delays.

\section{Results}

The effect of mechanical stabilization at the spring GAC Light $100 \mathrm{~g}-9 \mathrm{~mm}$ can be seen at the measurement comparison shown in chart (Fig. 2). Mechanical stabilization cycling ( 40 cycles) was performed before the "spring after stabilization" measurement. All the measurements were performed at constant temperature of $37^{\circ} \mathrm{C}$. The extension change speed was $2 \mathrm{~mm} \mathrm{~s}^{-1}$. 


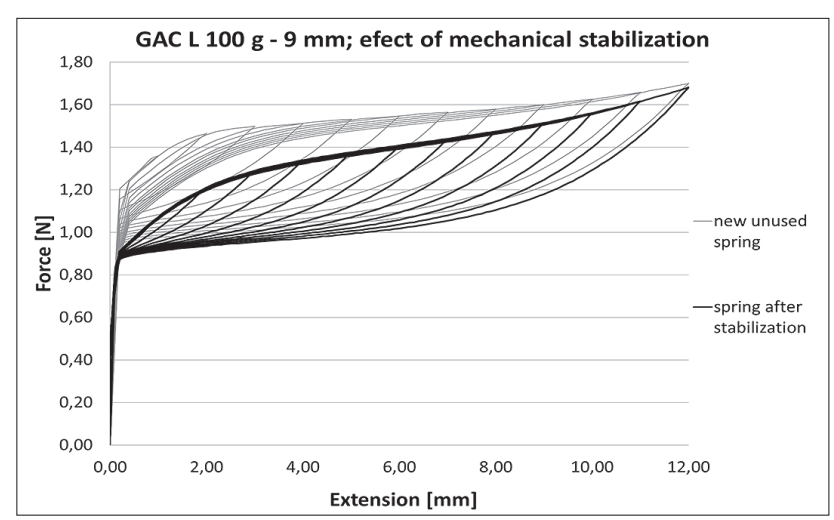

Fig. 2: Effect of mechanical stabilization

The chart (Fig. 3) depicts testing of force degradation over time of GAC Light $100 \mathrm{~g}-9 \mathrm{~mm}$ with mathematic model application of triple exponential function and the constant term. The spring was extended by $6 \mathrm{~mm}$. Afterwards the spring force values were measured at this constant deformation within $1800 \mathrm{~s}=30$ minutes. The measurement was performed at constant temperature of $37^{\circ} \mathrm{C}$. Regression models $F=A e^{-B t}+C e^{-D t}+E e^{-F t}+G$ were applied to measured data. By this we obtained a model course and its relevant parameters.

The chart (Fig. 4) shows progressive spring (GAC Light $100 \mathrm{~g}-9 \mathrm{~mm}$ ) force degradation due to mechanical stabilization and also due to force degradation over time at constant deformation itself. "Extension 6 mm ORIG" curve implies the force course of new unused spring for maximal extension of $6 \mathrm{~mm}$. "Extension $6 \mathrm{~mm}$ " curve implies the force course of mechanically sufficiently stabilized spring by many previous measurements and cyclings (time delay between both measurements is about 9 months). "Extension $12 \mathrm{~mm}$ " curve shows force course for maximal extension of $12 \mathrm{~mm}$. "Force degradation" curve shows the whole course of time force degradation measurements at constant extension of $6 \mathrm{~mm}$ including initial run-up extension and its final shortening to the original length. The short straight

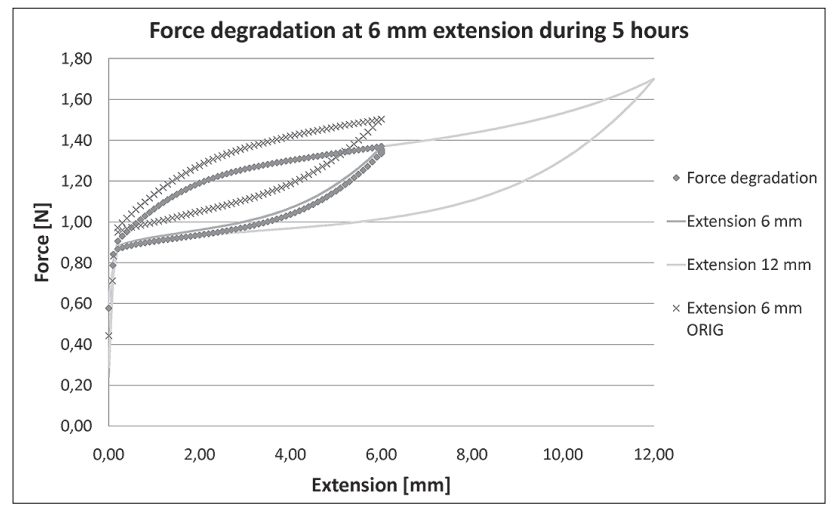

Fig. 4: Comparison of curve courses at various spring degradation phases

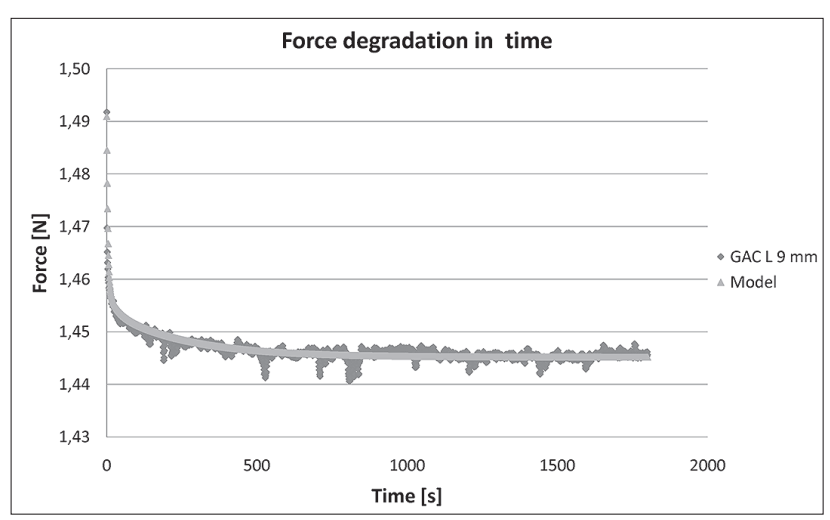

Fig. 3: Force degradation over time

vertical part (parallel to $y$ axis - marked Force [N]) is the force degradation course itself at the constant extension of $6 \mathrm{~mm}$ (there are the same data as in chart [Fig. 3]). The measurements "Extension $6 \mathrm{~mm}$ ", "Extension $12 \mathrm{~mm}$ ", "Force degradation" were done immediately subsequently.

The table (Tab. 2) of discovered parameters of time force degradations determines the nominal force decrease of springs in percentage for the first 30 minutes of permanent load.

Furthermore in our measurements we discover no impact of extension change speed, no impact of time delay on curve course between testing cycles and relatively negligible spring regeneration abilities in order of several percent of the original force value.

Tab. 2: Discovered parameters of force degradations over time for individual tested springs

\begin{tabular}{|l|l|}
\hline $\mathbf{9} \mathbf{~ m m}$ & \\
\hline producer & force degradation \\
\hline & in first 30 min [\%] \\
\hline $3 \mathrm{M}$ & 2 \\
\hline American Orthodontics & 3 \\
\hline Dentaurum & 2 \\
\hline Dentaurum & 2 \\
\hline GAC & 3 \\
\hline GAC & 3 \\
\hline Ortho Organizers & 2 \\
\hline \multicolumn{2}{|l}{} \\
\hline $\mathbf{1 2}$ mm & \\
\hline producer & force degradation \\
\hline \multicolumn{2}{|l|}{ in first 30 min [\%] } \\
\hline $3 \mathrm{M}$ & 1 \\
\hline American Orthodontics & 2 \\
\hline Ortho Organizers & 1 \\
\hline
\end{tabular}




\section{Discussion}

\section{Elastic properties of material and geometric structure of a spring}

In the chart (Fig. 2 - "not stabilized" curve) we follow the result of new unused spring cycling. Individual stressstrain curves move and every following curve relatively exactly goes through the extension maximum of the previous one. Apparently the next spring behavior depends on the highest extension it went through during previous testing. Afterwards it "relaxed" for 30 days. Then after next $40 \mathrm{cy}-$ cles the spring was "settled" and there weren't noticeable differences between single sequential measurement cycles (Fig. 2 - "after stabilization" curve).

We came to the similar conclusion as Wichelhaus et al. (16) that the new unused spring is mechanically stabilized after some cycles and noticeable differences don't occur at constant measurement conditions during measurement cycling. It means that the upper parts of stress-strain curves overlap and in case of repeated cycling with the same maximal extensions neither significant movements nor shape changes of the stress-strain curve occur.

\section{Viscous properties of the material}

Due to differences in the behavior of individual springs concerning the stress-strain curve shape - (Fig. 5), and the variability during cycling we expected the existence of a viscous component in the spring material. It impacts the spring behavior during dynamic, variable in time, loading. We tried to optimize the speed of spring stretching and time delays for sufficient spring regeneration.

For the sufficiently mechanically stabilized spring we observed that no noticeable changes occur at this spring

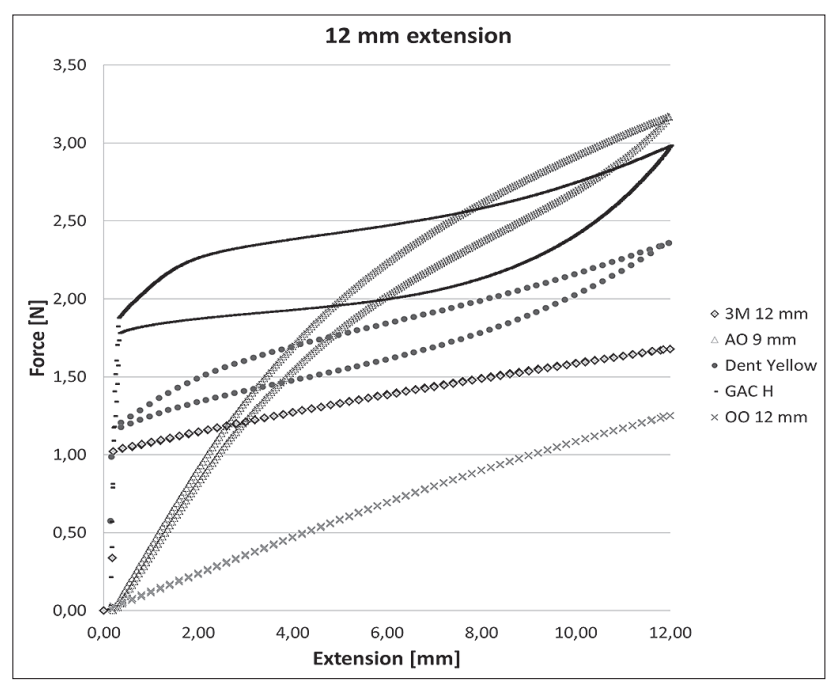

Fig. 5: Comparison chart of load curves of certain springs for $12 \mathrm{~mm}$ extension between cycling with and without time delays. Short delays between individual cycles won't have an important impact on the measurement result.

We discover no significant impact on stress-strain curve course due to moving speed. Maybe only a negligible stress-strain curve turning/rotation occurs.

We also compared stress-strain curves obtained immediately after previous cycling and then after 3 days of relaxation. Used extensions of the spring and measuring conditions were identical. Visible but relatively negligible spring regeneration, in order of several percent of the original force value, appeared in force increase at relevant extension in percentage. However, neither shape changes nor stress-strain curve rotation occurred. The whole stressstrain curve moved up into higher force values after regeneration.

Already published works dealing with the degradation of force over time clarify that the force decreases mainly during the first hours of constant load $(1,18-19)$. So we chose time force degradation measurements at constant extension with sufficiently gentle measuring step. After the application of theoretical model we found out that the real data correspond best to a curve consisting of three exponentially decreasing function and an intercept. Performing regression of the model for obtained data we found out individual parameters of the relevant mathematic function. The existence of three exponential functions is analogous to appearance of three viscous parameters which implies three separate decreases. The first rapid and large decrease during a few seconds, the second slower in range of minutes to tens of minutes and the third long term decrease in range of days or tens of days. The maximal force decrease takes place during the first tens of minutes after loading the spring. The intercept represents the value which the spring force is limitedly approaching to (theoretically it will be reached in infinitely long time). From the practical point of view it is reached during several tens of minutes or hours. We can see the data approximation in the chart (Fig. 3). During further control measurements we came to force decreases of about 3\% during first hours of constant spring deformation. These results correspond to previously published data (1). According to Angolkar et al.: NiTi force decreases about 3-11\% during first 4 hours and $8-17 \%$ during 28 days. In case of the NiTi spring $200 \mathrm{~g}$ GAC L $-9 \mathrm{~mm}$ measured that way is $26 \%$ decrease of force caused by its hysteresis whereas force decrease caused by its degradation over time is maximally $8 \%$ in 28 days (1). Measured force degradations for individual springs during the first 30 minutes can be found in the table (Tab. 2).

The final prove is the measurement in the chart (Fig. 4). Comparison of two simple $6 \mathrm{~mm}$ extensions, one them ("Extension $6 \mathrm{~mm}$ ") fixed for the time of 5 hours, and full extension of $12 \mathrm{~mm}$ clarifies that at $6 \mathrm{~mm}$ extension neither due to mechanical stabilization nor time force degradation the reverse plateau can be reached and used in full exten- 
sion (12 mm). During mechanical stabilization and force degradation - as the chart shows (Fig. 4) - only the movement of the whole stress-strain curve occurs - it decreases in the chart of the force dependence on extension, but it retains its shape. Even if its force decreases at the extension of $6 \mathrm{~mm}$ after a long term usage to values of a preactivated spring with maximal extension of $12 \mathrm{~mm}$ in its reverse plateau, the spring force at the tooth movement and by that at its shortening from its maximum of $6 \mathrm{~mm}$ would further decrease nonlinearly within nearly the same curve shape like at a new spring extended to $6 \mathrm{~mm}$.

Time force degradation and mechanical stabilization of the spring causes only seemingly the curve decrease, but not the movement within its individual stress-strain phases in force dependence on extension. The problem is that the decrease caused by the hysteresis is connected with transformations between material phases and is typical for special NiTi materials. Time force degradation and its mechanical stabilization is connected with viscous properties - "flowing" the material at being loaded, inclusions formation, structural disorders and changes generally, changes of mechanical bond etc.

We consider these results as a cornerstone for future research, especially for testing methods designing, as well as knowledge base for dentistry students' education - as we are performing at our department $(20,21,22)$. We see the importance of these results for orthodontic praxis as well.

\section{Conclusions}

Springs should be mechanically stabilized before their application.

The degree of force degradation over time is insignificant for mechanically stabilized springs.

Degradation or regeneration of force over time, mechanical stabilization or micromovements in the mouth do not cause any transition between individual stress-strain curve phases. Loss of reverse plateau does not occur. That means none of the possibilities mentioned above can be used to achieve the reverse plateau.

\section{Acknowledgements}

Supported by the programme PRVOUK P37/09.

\section{References}

1. Angolkar PV, Arnold JV, Nanda RS, Duncanson MG Jr. Force degradation of closed coil springs: an in vitro evaluation. Am J Orthod Dentofacial Orthop 1992 Aug; 102(2): 127-33.

2. Darendeliler MA, Darendeliler H, Üner O. The drum spring (DS) retractor: a constant and continuous force for canine retraction. Eur J Orthod 1997 Apr; 19(2): 115-30.

3. Liu SS-Y, Kyung H-M, Buschang PH. Continuous forces are more effective than intermittent forces in expanding sutures. Eur J Orthod 2010 Aug; 32(4): 371-80.

4. Tripolt H, Burstone CJ, Bantleon P, Manschiebel W. Force characteristics of nickel-titanium tension coil springs. Am J Orthod Dentofacial Orthop 1999 May; 115(5): 498-507.

5. Miura F, Mogi M, Ohura Y, Karibe M. The super-elastic Japanese NiTi alloy wire for use in orthodontics. Part III. Studies on the Japanese NiTi alloy coil springs. Am J Orthod Dentofacial Orthop 1988 Aug; 94(2): 89-96.

6. Manhartsberger C, Seidenbusch W. Force delivery of Ni-Ti coil springs. Am J Orthod Dentofacial Orthop 1996 Jan; 109(1): 8-21.

7. Samuels RH, Rudge SJ, Mair LH. A clinical study of space closure with nickel-titanium closed coil springs and an elastic module. Am J Orthod Dentofacial Orthop 1998 Jul; 114(1): 73-9.

8. Samuels RH, Rudge SJ, Mair LH. A comparison of the rate of space closure using a nickel-titanium spring and an elastic module: a clinical study. Am J Orthod Dentofacial Orthop 1993 May; 103(5): 464-7.

9. Bennett JC, McLaughlin RP. Controlled space closure with a preadjusted appliance system. J Clin Orthod 1990 Apr; 24(4): 251-60.

10. Han S, Quick DC. Nickel-titanium spring properties in a simulated oral environment. Angle Orthod 1993 Spring; 63(1): 67-72.

11. Webb RI, Caputo AA, Chaconas SJ. Orthodontic force production by closed coil springs. Am J Orthod 1978 Oct; 74(4): 405-9.

12. Maganzini AL, Wong AM, Ahmed MK. Forces of various nickel titanium closed coil springs. Angle Orthod $2010 \mathrm{Jan} ;$ 80(1): 182-7.

13. Boshart BF, Currier GF, Nanda RS, Duncanson MG Jr. Load-deflection rate measurements of activated open and closed coil springs. Angle Orthod 1990; 60(1): 27-32; discussion 33-34.

14. Záhora J, Bezrouk A, Hanus J. Models of stents - comparison and applications. Physiol Res 2007; 56 Suppl 1: S115-121.

15. Bezrouk A, Hanuš J, Záhora J. Temperature characteristics of nitinol spiral stents. Scripta Medica Facultatis Medicae Universitatis Brunensis Masarykianae 2005; 78(4): 219-26.

16. Wichelhaus A, Brauchli L, Ball J, Mertmann M. Mechanical behavior and clinical application of nickel-titanium closed-coil springs under different stress levels and mechanical loading cycles. Am J Orthod Dentofacial Orthop 2010 May; 137(5): 671-8

17. Havránek A. Úvod do bioreologie. Praha: Karolinum 2007.

18. Santos ACS, Tortamano A, Naccarato SRF, Dominguez-Rodriguez GC, Vigorito JW. An in vitro comparison of the force decay generated by different commercially available elastomeric chains and NiTi closed coil springs. Braz Oral Res 2007 Mar; 21(1): 51-7.

19. López N, Vicente A, Bravo LA, Calvo JL, Canteras M. In vitro study of force decay of latex and non-latex orthodontic elastics. Eur J Orthod [Internet] 2011 Jan 13 [cited 2012 Jan 27]; Available at: http://www.ncbi.nlm.nih.gov /pubmed/21239396

20. Hanus J, Nosek T, Zahora J, Bezrouk A, Masin V. On-line integration of computer controlled diagnostic devices and medical information systems in undergraduate medical physics education for physicians. Physica Medica [Internet] [cited 2012 Oct 12]; (0). Available from: http://www.sciencedirect.com/science/article/pii /S112017971100158X.

21. Zahora J, Hanus J, Masin V, Bezrouk A. Automated data acquisition and FEM virtual experiments in teaching medical biophysics. Proceedings of the 10th IASTED International Conference on Computers and Advanced Technology in Education, 2008, p. 329-33.

22. Hanus J, Zahora J, Masin V, et al. Computer aided learning and training on the platform of medical information system. Proceedings of the 10th IASTED International Conference on Computers and Advanced Technology in Education, 2008, p. 373-7.

\section{Corresponding author:}

Aleš Bezrouk, Ph.D., Department of Medical Biophysics, Charles University in Prague, Faculty of Medicine in Hradec Králové, Šimkova 870, 50038 Hradec Králové, Czech Republic; e-mail: bezrouka@lfhk.cuni.cz 